\title{
Zoltàn Dörnyei, Research Methods in Applied
}

\section{Linguistics}

Oxford : Oxford University Press, 2007

\section{Marie-Françoise Narcy-Combes}

\section{CpenEdition}

\section{Journals}

Édition électronique

URL : http://journals.openedition.org/asp/294

DOI : $10.4000 /$ asp. 294

ISBN : 978-2-8218-0406-7

ISSN : 2108-6354

\section{Éditeur}

Groupe d'étude et de recherche en anglais de spécialité

\section{Édition imprimée}

Date de publication : 1 novembre 2008

Pagination : 197-198

ISSN : 1246-8185

\section{Référence électronique}

Marie-Françoise Narcy-Combes, «Zoltàn Dörnyei, Research Methods in Applied Linquistics », ASp [En ligne], 53-54 | 2008, mis en ligne le 31 décembre 2009, consulté le 21 septembre 2020. URL : http:// journals.openedition.org/asp/294 ; DOI : https://doi.org/10.4000/asp.294

Ce document a été généré automatiquement le 21 septembre 2020.

Tous droits réservés 


\section{Zoltàn Dörnyei, Research Methods in Applied Linguistics}

Oxford : Oxford University Press, 2007

Marie-Françoise Narcy-Combes

\section{RÉFÉRENCE}

Dörnyei, Zoltàn. 2007. Research Methods in Applied Linguistics. Oxford : Oxford University Press. 335 p. ISBN 978-019442-258-1. 
Research Methods in Applied Linguistics est un ouvrage pratique et accessible qui s'adresse en priorité au chercheur débutant et au doctorant en linguistique appliquée et en didactique des langues pour lesquels il représente un accompagnement fort utile. Son style clair et son organisation sans surprise en font une lecture facile et agréable et rendent les différents concepts aisément compréhensibles pour tous.

Il présente un bilan de la méthodologie de la recherche en linguistique appliquée, du recueil de données à la publication des résultats. Zoltàn Dörnyei y explore les approches qualitatives, quantitatives et mixtes - c'est-à-dire combinant des méthodologies qualitatives et quantitatives - dont il propose une description critique détaillée.

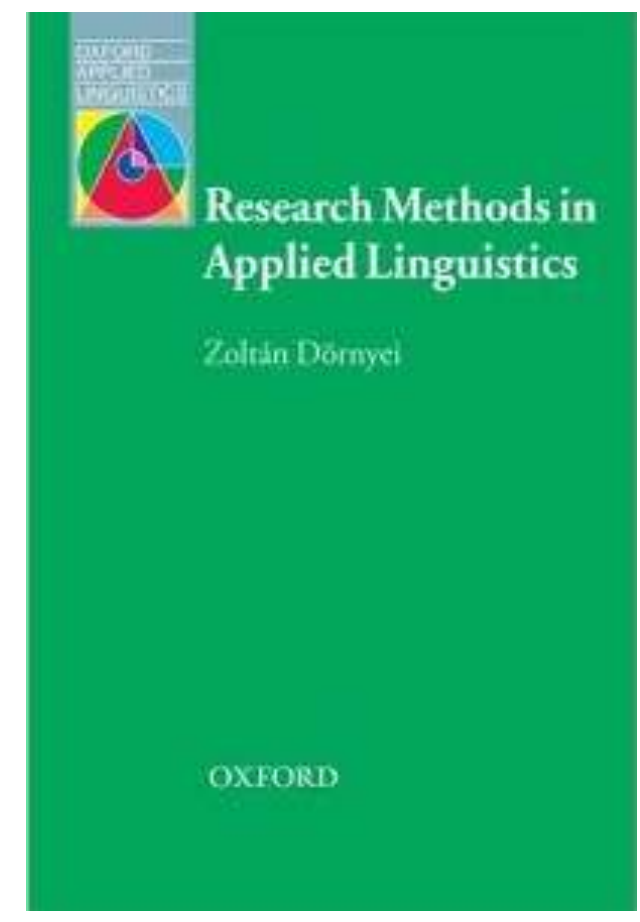

La première partie de l'ouvrage explore les concepts clés de la méthodologie de la recherche en sciences humaines, en partant d'une définition simple de la recherche comme le processus mis en place pour répondre aux questions que se pose un chercheur. Les notions de recherche quantitative, qualitative et mixte sont alors définies, les questions d'éthique abordées, ainsi que la différence entre les recherches longitudinales et les recherches transversales. On regrettera cependant qu'il ne soit pas proposé dans cette partie d'analyse épistémologique permettant de relier les différentes approches au positionnement du chercheur.

4 Les trois parties qui suivent développent ce premier chapitre et concernent respectivement le recueil de données, leur analyse, puis la publication des résultats en adoptant successivement le point de vue quantitatif, qualitatif et mixte. Le chapitre huit de la deuxième partie est consacré à la recherche sur le terrain (classroom research) et à sa spécificité ; il inclut des remarques sur l'observation de classe et les difficultés liées à ce type de recherche. L'ouvrage s'achève sur une très courte cinquième partie intitulée « summing up » mais qui, plutôt qu'un résumé, est en fait un appel au bon sens. Elle offre des recommandations très pratiques sur la façon de mener une recherche, de choisir un directeur et de garder à l'esprit le rôle social de la recherche menée.

Il s'agit ici d'un ouvrage essentiellement descriptif et pratique, illustré de nombreux exemples et accompagné de conseils pour faciliter l'accès du chercheur néophyte aux techniques spécifiques de la recherche en linguistique appliquée et en didactique des langues. Les chercheurs confirmés y trouveront l'organisation claire et exhaustive des méthodes de recherche qu'ils connaissent déjà. 


\section{AUTEURS}

MARIE-FRANÇOISE NARCY-COMBES

Université de Nantes 